\title{
SOCIAL AND HEALTH FACILITIES: HEALTH POST PLANNING FOR A NEW CONSTRUCTIVE SYSTEM IN DEVELOPING COUNTRIES
}

\author{
Chizzoniti Domenico*, Cattani Letizia, Moscatelli Monica and Preis Luca \\ *PhD Associate Professor, Department of Architecture, Built environment and \\ Construction engineering, Polytechnic of Milan, Milan, Italy
}

\begin{abstract}
This paper tries to analyze a planning for Primary Health Care (PHC) facilities in developing countries through a flexible system construction in order to realize a multi-scale prototype adaptable in different contexts.

While Emergency Medical Assistance (EMA) is delivered in disasters or emergency situations, Primary Health Care is based on a support as part of overall development constructing as best multi-purpose facilities that can be adapted as a social for different tasks and activities. With this approach, we examine the process of building system structure for different functions by adapting the flexible system to the different countries, areas and settlements.

The aim is to define guidelines for planning health facilities with multi-criteria approach, identifying a score to the same factors relating to different contexts. This paper describes a new process to define a program for a flexible, modular and expandable system for health facilities.
\end{abstract}

\section{KEYWORDS}

Primary health care, developing countries, health post, design modular system

\section{INTRODUCTION}

Health in developing countries is the sector that is in crisis more quickly, thus becoming unsuitable and dramatically worsening the life quality of population.

Health care in a society in development focuses on Primary Health Care (PHC) that has the objective to promote health and offer assistance to local population, through polyvalent health facilities that provide human development and wellbeing. At the opposite pole, Emergency Medical Assistance (EMA) refers to disasters or emergencies: earthquakes, floods, migrations, tsunamis, terrorist attacks, wars and economic crises.

These two different strategies have often been confused; the links to the context in which they are applied are different, as well as the objectives, the resources used, the social dimensions, and the time perspectives [1]. Even the systems usually employed in emergency situations are often improperly used as health care unit in developing countries. It is not believable that the facilities used for emergency situations are adopted for primary health care. These systems, delivered in disaster and survival conditions, are characterized by a method of dry assembly, ease and speeds of installation. Most prefabricated systems are designed through a logic of "closed" systems, they reduce the project flexibility, getting strictly defined configurations both in terms of typology and technology applied. 
A primary health care approach needs a flexible and adaptable method able to acquire the principle of self-sufficiency with "open" systems, thus avoiding any fixed solutions [2]. The search result is primarily to define a flexible, expandable and versatile facility through a construction system and a logical settlement that can be expanded according to site requirements. It needs to relate to the different application contexts also in terms of finding construction materials, as well as typological and localization models of each local settlement.

Tents and inflatable systems, commonly used in the first stage of emergency, are in antithesis to a primary health care approach; they allow us to obtain quickly habitable spaces and can be easily assembled, but they have an improper acoustic and thermal insulation, which undermines the space efficiency of health care facilities. Furthermore, they are temporary structures with a short-term effectiveness, as opposed to the strategy of PHC services, which require a long-term perspective.

An alternative to the tent is offered by the prefabrication systems with container and prefabricated housing units [3]. The employment of these elements is justified by an extended period of use; compared with the tent, the assembly time is increased due to the identification of a suitable area in relation to the possibility of restoring the road network, levelling and consolidating the area placement. The container was designed for goods and does not work for people, much less for social and health facilities.

In conclusion, this article aims to focus the attention on basic health service in developing countries, which has the purpose of ensuring the proper functioning of primary health care and education, especially in decentralized areas. The aim of this paper is to create a planning procedure able to complete the peripheral segments of care still lacking the health systems employed in many contexts of sub-Saharan Africa and suitable for exporting to other countries with high social marginalization.

\section{STATE OF THE ART}

The Universal Declaration of Human Rights endorsed the prominence of right to health for everyone. This statement was confirmed in 1977 as a human right following the declaration of the 30th World Health Assembly, "Health for All by the Year 2000" [4]. In the last decade, all scientific studies showed that the priority for most people in third world countries need health care interventions at a rather basic level, in order to reduce the mortality caused by diseases and injuries [5]. Of course, ensuring access to clean water and sanitation, battling ongoing communicable diseases and stemming the tide of preventable deaths still rule the healthcare agenda in many countries.

Nevertheless, the incidence of life-threatening chronic diseases is rising fast. This represents a new challenge for Africa's healthcare system [6]. A growing number of Africans are still unable to properly access treatment provided by donors and governments, and many countries have recently begun acknowledging the importance of preventive methods over curative action.

At the same time, some countries are experimenting with different forms of universal health provision. These basic interventions are gathered under the name of "Primary Health Care" (PHC) whose principles were definitely stated in the Declaration of Alma-Ata, which was held in the Soviet Union in 1978, following the International Conference sponsored by the World Health Organization (WHO) and UNICEF [7].

The Harare Conference was held in 1987, after the Alma-Ata declaration, developing the program of "Selective Primary Health Care" as a response to the difficult implementation of PHC [8]. 
The goal of these conferences was to provide a response to growing expectations for a new public health movement around the world. Thanks to them, the importance of Primary Health Care was underlined and it was recognized as an integral part of a country's healthcare system. For that reason, in order to carry out PHC systems, many countries need to direct their policies, strategies and resource allocation, and overcome the cultural and political barriers. As a result, this strategy requires them to focus on rural areas and on the most deprived urban ones, where the primary needs and pathologies of the poorest people are so widespread [9].

In several cases, although health officials declare that their national priorities should include the improvement of hygienic conditions, infection control and primary health care in rural areas, a large amount of the money put aside for PHC seems to be more frequently allocated to major urban hospitals [10].

In most developing countries, the health care system has the task to increase the community awareness of the causes underlying diseases. According to the Health Situation Analysis in the African Region, (Atlas of Health Statistics 2011 by World Health Organization), the disabilityadjusted life-year (DALY) provides a consistent and comparative description of the burden of diseases and injuries needed to assess the comparative importance of diseases and injuries in causing premature death, loss of health and disability in different populations [11] (Figure 1).

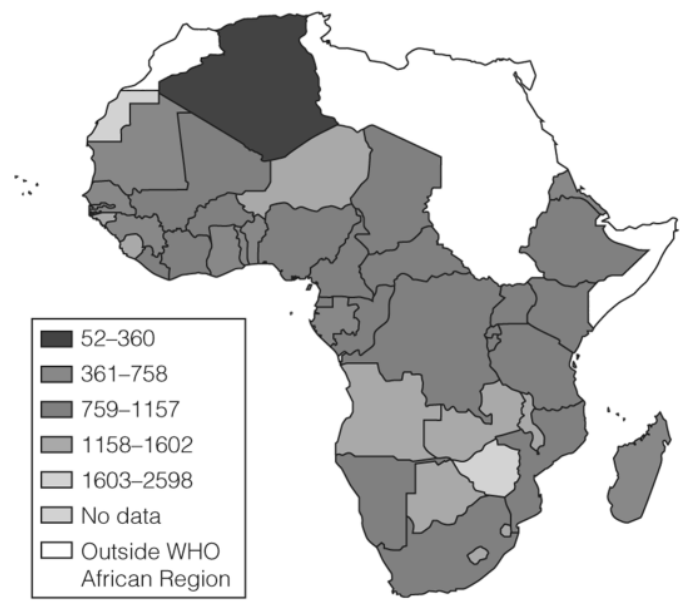

Figure 1. Age-standardized death rates per 100000 population due to communicable diseases in the Africa Region, 2004 (Atlas of Health Statistics 2011 by World Health Organization)

The DALY extends the concept of potential years of life lost due to premature death to include equivalent years of 'healthy' life lost by virtue of being in states of poor health or disability. These may include domestic causes such as contaminated water, lack of services or sewerage, waste disposal, lack of attention to personal hygiene and preservation, processing and preparation of food.

Providing medical care can bring only limited progress if there is not a program to improve housing conditions, prevention and health education. Therefore, the aim of the new program for PHC is to increase the improvements regarding the access to safe drinking water. Nowadays, the sanitation system has also stalled in Africa, thus making it difficult to combat the high levels of waterborne illnesses. As a result, parasitic diseases continue to wreak havoc in many areas of Sub Saharan Africa.

The health care in a developing country, particularly in rural areas, must preliminarily carry out the task of education and leadership in the community [12]. 


\subsection{Health facilities: projects in the past}

In the twentieth century some architects have dealt with health issues, designing health facilities not only in urban areas, but also in rural ones.

American architect Richard Neutra created some remarkable examples of social architecture in rural areas in the projects. He is best known for his houses, but he designed many noteworthy large-scale projects all over the world, more often public rather than private commissions. Puerto Rico was an important time and place in Neutra's career. The semi-tropical setting he fell in love with during his two-year assignment was idyllic in its geographical beauty but in sharp contrast to the desperate illiteracy, disease and malnutrition he encountered. Here a systems approach to building was not a luxury but a necessity. Structures had to be put up rapidly on a very lean budget, and still be able to withstand hurricanes and wind storms [13].

Neutra set up an office in Puerto Rico in fall 1943 and stayed until spring 1945. He designed over 150 village and rural classrooms, about 130 rural health centres, nursing schools, four district hospitals, dormitories and houses for medical staff. Neutra rejoiced in the challenge of creating a viable, cheap architecture, which could be quickly assembled by local labor, an architecture, avoiding an institutional character, which would have put off the very people it aimed to help (Figure 2).
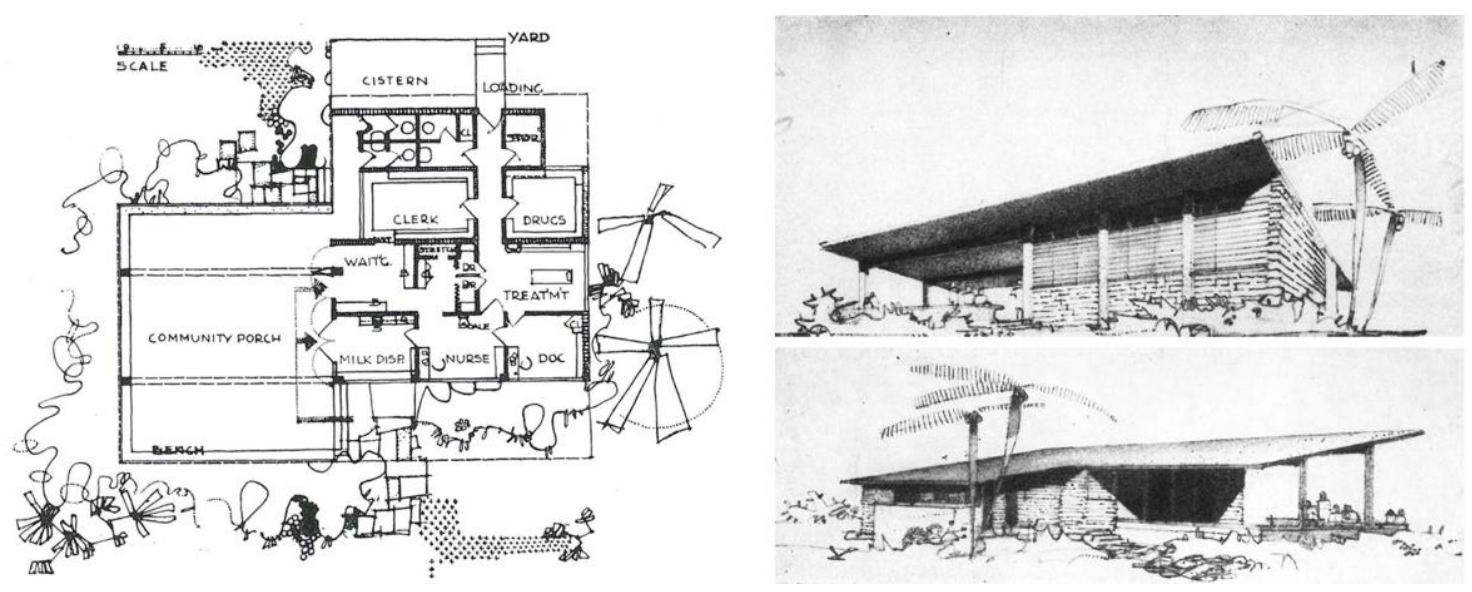

Figure 2. Richard Neutra-Rural Health sub-center: floorplan, front view and back view (R. Neutra, Arquitetura social em paises de clima quente, Sao Paulo: Gerth Todtmann, 1948)

He studied local social, economic, climatic and geographical conditions exhaustively, writing lyrical passages in letters about the haunting beauty of this then-impoverished island. Both classrooms and medical facilities were masonry-built and intended to respond elastically to changes in use and personnel. In the community centers, covered patios and central fountains created welcome transitions and gathering places that also responded to local culture and traditions. Prefabricated storage units were supplied for every conceivable educational aid [14].

\subsection{Health facilities: recent projects in rural areas}

Among the recent health facilities in rural areas, remarkable from architectural point of view is the CBF (Centre pour le Bien-être des Femmes) Women's Health Centre in Burkina Faso was created by AIDOS, an Italian NGO fighting for Women's Rights in Developing Countries. The social/health-services program developed by AIDOS, together with its local partners, focuses on providing educational services, information and awareness about women's sexual and reproductive rights in Ouagadougou's Sector 27, a peripheral urban area settled by a once rural 
population. The architectural project is a direct response to a social program that called for the realization of a building complex capable of hosting a variety of activities in very harsh circumstances. Completed in 18 months by a local builder, it simultaneously represented a centre of aggregation and identity for the entire local community. The project privileges an integrated approach to interaction between built space and climatic-environmental issues, based on considerations of sustainability and appropriateness. The design is based on the separation of the primary activities performed by the CBF into two distinct, though closely related, buildings: a Training Centre, dedicated to management and awareness-rising activities and a Consultancy Centre, where medical visits, legal assistance and psychological counselling are provided to the community almost free of charge. The modular configuration of the structure allows future expansion while preserving the general framework of the building. The CBF, winner of the HEALTH category award at the World Architecture Festival of Barcelona 2008, has been awarded a special prize at the Philippe Rotthier Architecture Prize 2014 and was shortlisted among the finalists for the 2010 Aga Khan Award for Architecture. The building is intensively in use [15].

Another project in Burkina Faso is the Surgical Clinic and Health Center by the architect Diébédo Francis Kéré completed in 2014. These modules, combined together, allow The Center is equipped with surgical facilities, an in-patient ward, and a maternity unit. In planning for the most sustainable building solution with least ecological impact, the main construction of the Center is compressed earth bricks. Their high thermal mass capacity allows them to absorb the cool night air and releases it during the day, helping keep the interior spaces cool. The clinic also features ten large overlapping roofs that protect the walls from rain and shade the interiors and surrounding spaces from the hot daytime sun [16].

The Pediatric Health Clinic in East Africa designed in 2009 by FAREstudio is an interesting project from the point of view of the aggregation of modules. These modules, combined together, allow creating different spaces in which carry out various activities. The modularity allows the clinical centre to be expanded according to future needs. The health clinic aims to be a prototypical solution for health facility that is expanded in time to a set of guidelines, which are intended for unskilled operators [17].

\subsection{Primary Health Care: the role of a new structure}

The Health Post is the main structure of Primary Health Care's system. The Health Post is constructed as best multi-purpose spaces that can be adapted as a social facility for different tasks and activities [18]. It hosts more functions according to the context in which they are located and the needs of the population served. The demographic and geographical characteristics are important for understanding which services will be used the most and how the situation might change in the future [19].

At the beginning the Health Post, staffed by one community health worker, should be composed of four basic areas (a waiting area situated between an examination room and a storeroom subdivided for drugs and equipment, and a room subdivided for dressings and injections), with the possibility of a future expansion by integrating more functions [20].

In outlying areas, specific standards for health facilities and educational ones should be ensured, such as: peripheral health facilities to ensure primary care; system of care and services offered even to the most remote communities; training schools for health workers. This construction unit has a better potential for communication with the community than the hospital. The Health Post could thus become a health care and socio-cultural facility, giving people in rural areas the opportunity to improve their education with training and awareness on health issues concerning their country [21]. 


\section{NeW Problems and NeW Approach: Refocusing on Primary Health CARe}

Probably, within the next decade, many initiatives for improving health care will attract various African countries, in an attempt at making their healthcare systems sustainable.

In a few years, many African countries will have reorganized their health facilities, so as to emphasize primary care services, that educate people about healthy lifestyles, keep them in good health, operate with an ordinary system of first aid able to manage chronic conditions [22].

One of the most important aspects of this process will be a renewed focus on preventive care, in order to manage chronic illnesses, and promote wellness and health of rural population. In that case, it is possible to optimize and reduce expensive hospital stays [23].

The priority action, on one hand, has to regard massive immunization campaigns, which will include new vaccines against malaria and tuberculosis. On the other hand, it might be necessary to improve the behavioural change regarding sexual health and nutrition.

Focusing on Africa, change is likely to be uneven across the continent. Many advanced countries, such as South Africa, Kenya, Tanzania, Uganda, Nigeria and Mozambique can be organized by multi-tiered, high quality health delivery at both primary and secondary levels. Less-developed countries should concentrate their limited resources on primary care, prioritizing the wellbeing of many people over curing only few of them [24].

Many investments may be channelled into prenatal and pediatric care. In this case, the hospital role could be almost exclusively devoted to specialist care.

In such way, indeed, some countries, in an effort to cut hospital admissions more quickly, might resort to the "gatekeeper" approach used by managed care companies in the US, in which primary-care providers receive incentives for keeping people out of hospital.

This general strategy was described in a report by the Economist Intelligence Unit (2011) and focused on a few points [25]:

- health systems shift to focus on preventive rather than curative care;

- governments transfer healthcare decision making to the local level;

- telemedicine and related mobile-phone technology becomes the dominant means of delivering healthcare advice and treatment;

- universal coverage becomes a reality, giving all Africans access to a basic package of benefits;

- continued global instability forces many international donors to pull out of Africa or drastically cut support levels, leaving governments to fill the gaps.

According to this plan, the main problem in African countries is to fill the gap between curing illness and preserving health. In addition, according to healthcare providers, aid organizations and entrepreneurs, one of the biggest factors hampering Africa's ability to face its multiple health challenges is a structural one. The problem is that all the healthcare systems remain focused on acute, short-term treatment, on fighting the traditional battles against infectious and tropical diseases, diarrhoea, as well as maternal and child mortality.

The approach towards primary healthcare is changing due to the growing amount of chronic conditions and the increased populations coping with diseases for longer periods. Hence, new 
emphasis is put on preserving good health instead of investing in big and expensive new structures.

Ernest Darkoh, founding partner of Broad Reach Healthcare, said that the most successful outcome should be defined as never needing to see the inside of a hospital [26]. The continuous need to build more hospitals and clinics should be considered a sign of failure. "We must make disease unacceptable instead of building ever larger infrastructure to accommodate it", Ernest Darkoh adds.

With adequate resources available, public hospitals will be able to concentrate their attention on treating and curing the most serious cases. The other structures could invest in wellness campaigns, social education, and any other initiatives which may involve not only medical staff, but also other roles, such as officials dealing with agriculture, transportation, law enforcement, water and sanitation, food security and housing [27].

That strategy is characterized by the remarkable role of primary health structures, especially in rural areas, focused on education in order to avoid reliance on expensive and overstretched health workers and facilities.

\section{THE STRATEgY LOCALIZATION OF A NEW SYSTEM OF HEALTH FACILITIES}

The research strategy is to implement the existing health facility composed of Central Hospital, District Hospital, and Rural Health Centre, with a network of primary health services (Health Post) to be placed in rural developing countries.

Facilities should be organized hierarchically, with health centres supporting the Health Post surrounding them; finally, clinic services should be supported by a rural hospital (Figure 3).

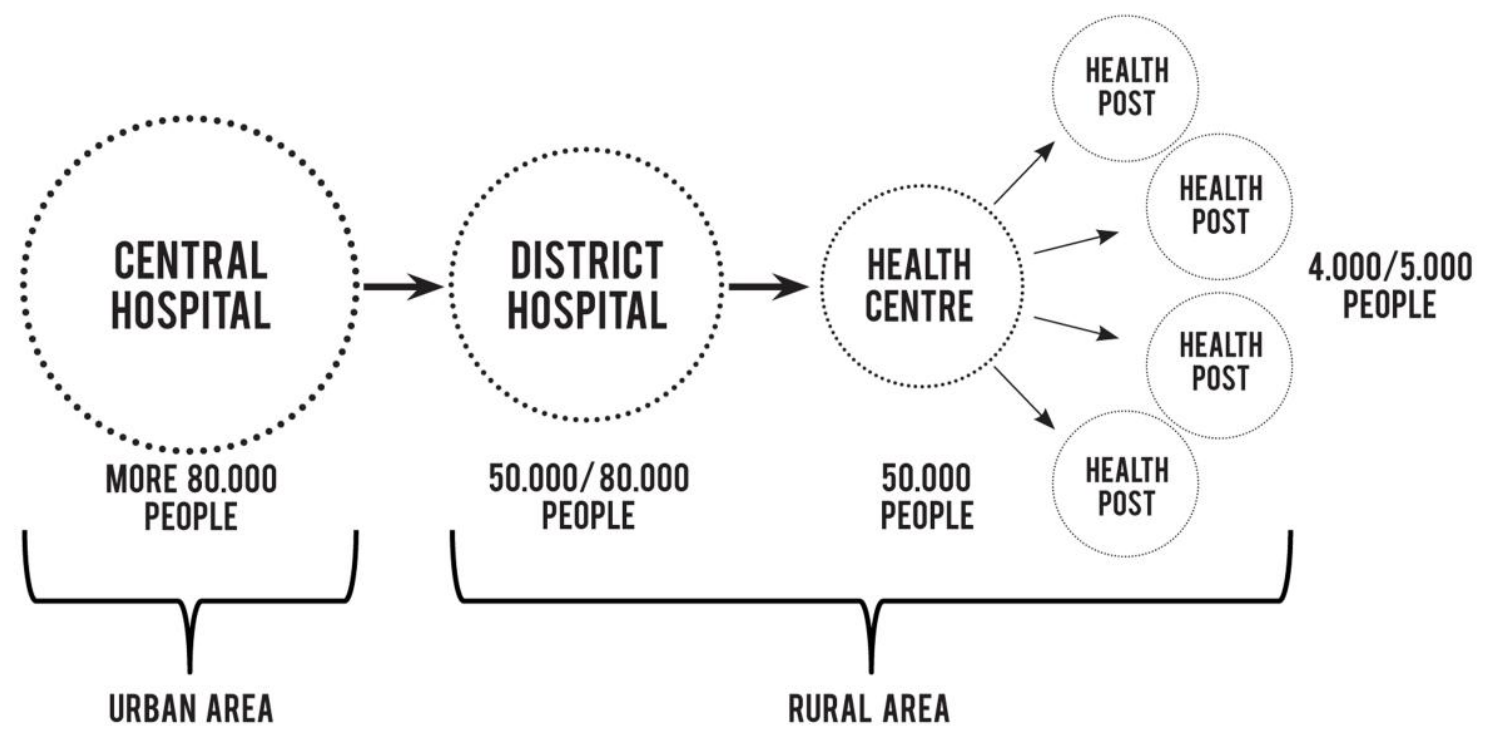

Figure 3. Health system network in developing countries 
The implementation of primary health care usually starts from a situation characterized by considerable inequities in the distribution of health resources; but it is urgent to determine, as soon as possible, in what direction to proceed.

A plan for health facilities is vitally important; obviously it should not be isolated, but it is an integral part of a global health strategy. It should also be developed in relation to multisectoral aspects of national planning. The principal functions of planning are the allocation, organization and evaluation of resources (human, technological, physical), which are defined equally for all areas. The development of inappropriate buildings is often due to the lack of well-documented guidelines; this absence hampers the work of architects and planners [28].

However, the production of the most relevant publications has led to a beneficial effect in the way of thinking, therefore now there is a more solid basis for establishing advanced guidelines, which help to plan logically, easily identifying problems and solving them rationally.

Emphasis must be placed on the different levels of health facilities. These levels must try to have a typical division of tasks without overlapping functions; any failure to do something at the Health Post should be solved at the hospital, and vice-versa. The work of basic health units and of hospitals is distinct and complementary. It is the primary level of health system that has to built up [29].

The Health Post has specific advantages over the hospital; these advantages can be distinguished in three domains: primary curative care, preventive care, and contacts with the community.

The general approach model refers to the concept of Local System of Health (SILO), developed by the Pan American Health Organization which focuses on principles relating to "Equity and quality of services, the democratization and social participation, development and economic and social transformation, the efficiency and the use of appropriate technology" and also "on an integral concept of health, well-being and development" starting from the basic medical unit of the Health Post.

These basic but essential health facilities, must be able to supply health services to all, but especially to those who need them most (equity), properly managing the limited financial (efficiency) and human resources (productivity).

The Health Post promotes the decentralization process: from a technical, financial and administrative perspective, within the health services that support it, aiming to adapt strategies and national programs to local realities. They shall be permanently sustainable and promote self-sufficiency. Therefore, any support should be excluded with regard to structures and programs which duplicate functions or are in competition with the national health systems.

Before analyzing the functional aspects of the health facility, it is important to choose the area where it will be placed. Whereas hospitals are located in towns and mainly serve urban settlements, Health Posts have to be placed in peripheral areas and serve peasants.

In the area in which one wants to act, a score should be identified to some factors, such as: population density, water supply, sanitation and waste disposal, access to public transport by giving a 'weight' to each of them. The weight is the average judgment for each factor, and it should be shown in the map of the area. Once this judgment is given, it is easy to detect the "stress" zones. This strategy aims to locate the basic health units in the areas with worst situations, close to main rural infrastructure networks, not far from villages, to reduce the impact of the distance between the residence and the peripheral health facility. If the distance 
between villages and Health Posts increases, the health care utilization decreases consequently, also because in developing countries the means of transportation most commonly used is 'walking' and roads are not paved; this makes it more difficult to reach basic health facilities by increasing the mortality rate of the local population.

Each Health Post should thus be distributed rationally within a catchment radius of 10-15 km, although it would be better to locate the primary health care unit no further than $5 \mathrm{~km}$ from neighboring villages. Identifying a range of health coverage will optimize the number of people gravitating to each Health Post [30].

The number of people per health unit is usually 3,000-5,000 people, but it depends on population density and on the flow of population, which changes according to the location of the Health Post and the care they need. There are some additional very important features, such as the conditions of life of the community and its particular needs, the prevalence of specific diseases and the socio-cultural conditions [31].

These basic health units should still be regarded as the first element of a larger system, since in the future they might need to expand, gradually turning into little hospitals.

\section{The role of the Health Post: an elementary Structure for Primary Health Care}

The Health Post is the first point of contact for the community; it is the "gate" of entry into the health system.

Primary Health Care is constructed as best multi-purpose spaces that can be adapted as a social facility for different tasks and activities. It hosts a varying amount of functions according to the context in which it is located and the needs of the population served. The demographic and geographical characteristics are important for understanding which services will be used the most and how the situation might change in the future [32].

In outlying areas, standards of health facilities and educational ones should be ensured, such as: peripheral health facilities to ensure primary care; system of care and services offered even to the most remote communities; training schools for health workers. This construction unit has a better potential for communication with the community than the hospital.

The Health Post could thus become a health care and socio-cultural facility, giving people in rural areas the opportunity to improve their education with training and awareness on health issues concerning their country.

It is also necessary to think of "social areas", organized out of the buildings as a piazza with some activities. Special waiting spaces can be provided as the size of the health care facility increases.

Therefore, hypothesis will be made about the creation of a minimum prototype for health to evolve over time, responding to new medical and social needs.

A health facility acts as a pole not only for attracting people but also for irradiating services on the territory. Therefore, it has to promote settlements, including all the activities needed by the population, such as health facilities, schools, markets and water wells, in order to ensure health and hygiene in villages (Figure 4). 


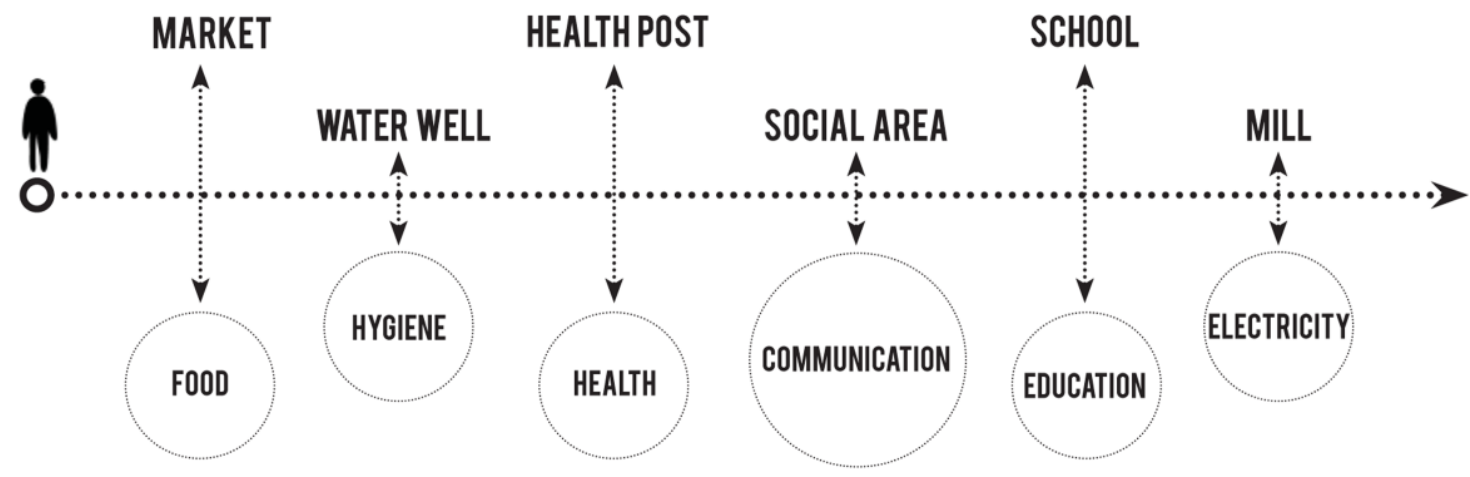

Figure 4. Network of services implementation

This fact does not only implies that the location of the construction unit should be barycentric with respect to the catchment area, but it also implies that only few services will be located in the center.

\section{Flexible, Modular, Expandable: A NEW CONSTRUCTION SYSTEM FOR DIFFERENT TERRITORIAL SITUATIONS}

A multi-purpose space therefore requires a flexible construction, which is suitable for different territorial situations, applying an alternative type and a technological system to those used so far.

The architecture and especially the design and technological experimentation should play the role of guide and comparison with the rules of production, with intervention strategies and with operational legislation. The real models in primary health care systems show a lack of attention to problems relating to the field of architecture and urban planning, showing an interest, rather than in actual housing needs, in the reduction of the problem, with the aim of its most immediate salability. The architectural design should provide a number of important innovations and interesting guidelines to produce a multi-scale prototype to be placed in different contexts. It is necessary to go beyond the succession of three intervention phases usually used: tent, container and prefabricated house, exceeding the temporary settlement with the stability.

The health unit is thought to be aimed at the acquisition of energy, the passive solar design, the control of shading, insulation techniques, controlled natural ventilation, natural and artificial lighting, storage of water, etc. A unique construction system able to operate for different usage purposes without changing the underlying logic, but simply adapting the structural geometry of the function and the built form to the site.

The most important architectural quality of a Health Post should be flexibility: flexibility in the movement between the spaces, flexibility for being able to change the functions inside the system and flexibility for growing and expanding.

A flexible space can be arranged in different ways by testing alternative solutions and choosing those most suitable for wider application [33].

The design method should be based on modules to obtain flexibility. For this reason, the multiscale prototype should be thinking with modular and reproducible elements to simplify the construction of healthcare facilities and provide design benefits. The project should be based on 
a modular grid to meet the needs of flexibility, aggregation and ease of assembly [34]. The first step for this research is the definition of the primary module. When choosing the basic module, a single modular dimension must be decided. A single module cannot allow optimal use of the space for some functions; the use of several modules would reduce the number of compromises necessary for different health facilities. Therefore, a system is efficient whenever it can satisfy more functions under two, three, or more different modules. An adaptive space system, that changes according to the situation of use. Continuous space systems that have the ability to take on several configurations and allow the maximum interchange of different activities between rooms [35]. The variability of how the living space can be used has introduced the concept of an accessible space. In 1987, Baudrillard, stated that the adjective "functional not qualify what is conformed to an aim, but what has adapted to an order or a system: the functionality is the ability to integrate into a set" [36].

The configuration of these modular elements will allow some flexibility to expand over time, adapting to different conditions of use allowing any change of position.

From creative act based essentially on operations of synthesis and generally done through graphic abstractions, the same architectural project becomes a cognitive analytic procedure that works for decomposition and re-composition of the terms of the design problem. In order to be suitable to the current dynamic facts, the solution cannot be unidirectional, but open to subsequent modifications in time and space according to the population it serves.

Therefore, the design objective of the operation does not merely include the final object as a concluded and immutable entity, but also its making, i.e. the definition of possible were training as a function of levels of variables performance. Not finished units, but parts between them properly congruent able to build multiple functional sets to variable configuration.

\section{THE FUNCTIONAL APPROACH TO THE THEME}

Since the PHC Centre is supposed to be the most basic way of supplying medical service, the spatial solutions should be very basic too. That is the reason why another step to begin could be to detect homogeneous spatial fields, which are spaces where more than one activity can be performed [37]. This also helps to individualize the spaces that may be planned with special attention to the cultural aspects. In other words, we can say that the health centre is going to be divided into specific and general purpose zones, which will have different requirements [38].

The spaces included in the specific purpose zone need to have a high level of definition, therefore the meaning of intervention has to be clear, while in the general purpose zone activities are common to a lot of functions with few demands to the built environment from a technological point of view. It might be necessary to introduce local and cultural patterns, materials and techniques in this zone as a planning method [39] (Figure 5).

The functional requirements and their implications modify the position and the presence of some rooms, that is why they have to be decided immediately [40]. Under conditions of limited resources, the possibilities for service rotation are the best way to provide in the same space different services in different days of the week. In doing so, the total required surface for the facility decreases, and so do the construction costs. 


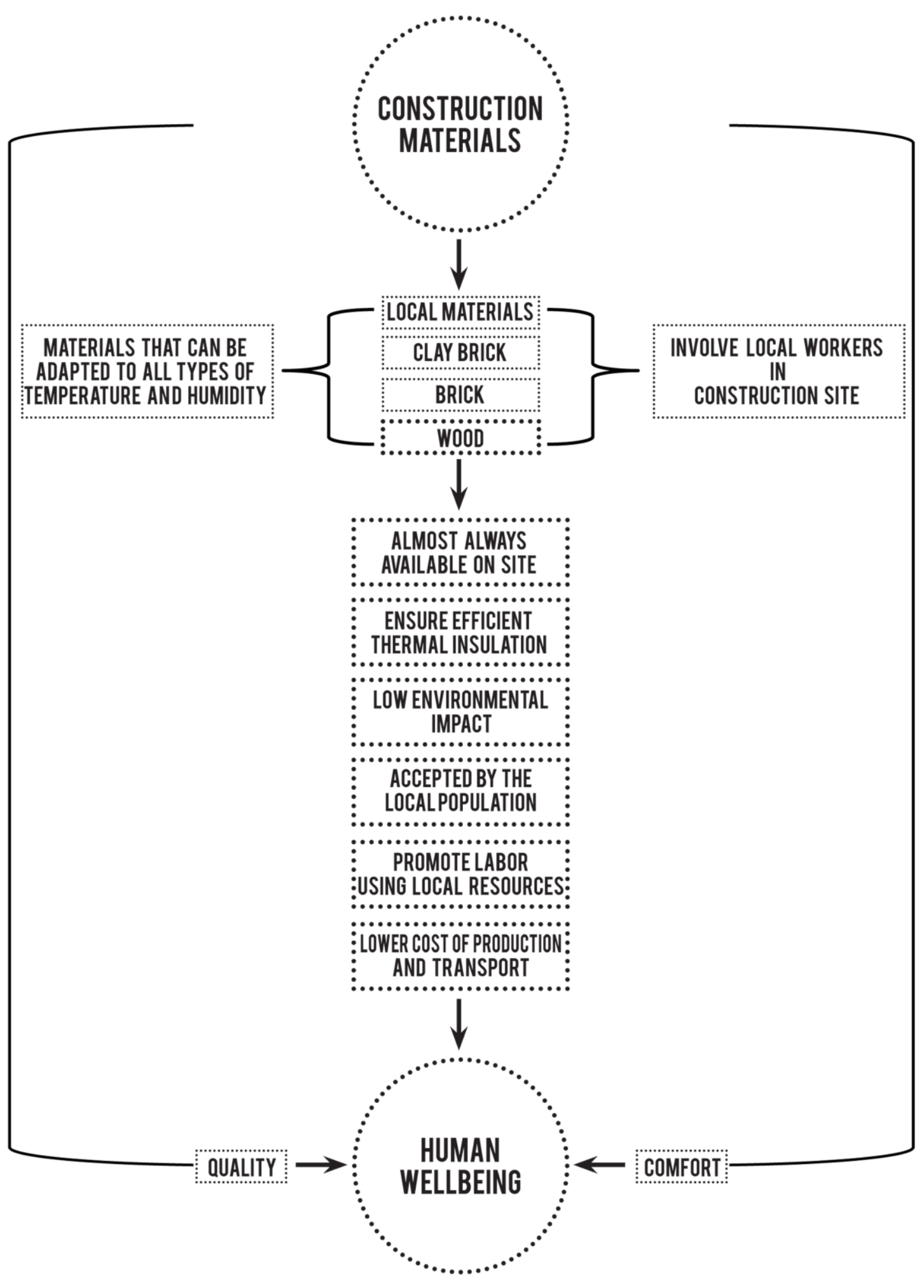

Figure 5. Materials and techniques construction as a planning method in developing countries 
Spatial solutions strongly influence the efficiency of the PHC Center. The primary health care has to be immediately recognized; therefore, it should be easy to move around. For this purpose, the decisions about position and number of access points to the center plot are important. In addition, a parking lot should be provided, with arrangements for bicycles, animals, etc. rather than for cars.

Flows of people and goods should be easy, straight and with few interruptions and overlapping. In order to guarantee this, it is better to provide some direct entrances for goods (drugs, medicine, etc.).

Staff movements should also be easy. It should be noted that they do not depend on the corridor shape, but on the possibility of having some dedicated "special routes". The PHC Center does not have enough space to contain a two-corridor system; therefore, it would be better to have door communications between adjacent rooms, which can generate a 'fake' corridor for staff. Moreover, in this solution it is possible to arrange some sub-waiting bays for people waiting [41]. People waiting are not only patients, but also relatives and friends, that is why an area where patients can leave children and friends should be provided [42]. This area may be called "social area" and should be organized out of the buildings as a piazza with some activity pockets. Special waiting spaces called sub-waiting bays can be provided when the size of the health care facility increases [43].

Reception and registration should operate in an informal and rapid manner. That is why the reception should be places in a barycentric position, so as to be clearly visible and accessible from all major entrances to the building, but without giving the impression of a controlling post.

Storing procedure is also important and should be considered in planning procedure. Due to the limited size of a PHC Center, these storage rooms should be as few as possible, even if each of them must be large enough to cope with the quantity of materials to be stored, and built in order to meet the needs of each specific material (safe from thieves, not humid for drugs and alimentary goods etc.).

\section{RESULTS}

Primary Health Care is a rather new approach to improve the quality of health care in third world countries. Therefore, we cannot see many examples around the world, which are designed with different methodologies and with interesting results.

As we analyzed the existing PHC Centers [44], we noticed that nearly nobody had an architectural approach towards them. The reason for this is the fact that these health centers have so far been built in a rather improvisational way, aiming to finish them and serve them to the public as soon as possible [45], sometimes using some small-sized existing buildings.

Through the analysis of existing examples, we understood how our approach should be defined and which the underlying principles should be. The first thing we noticed about these health centers had been how simple their structure was. All the functions that we talked about before were all reduced to one or two different closed spaces. In some cases, the activities such as entering, registration, main waiting were also placed outside.

The most important architectural quality of a PHC Center should be flexibility; flexibility in the movement between the spaces, flexibility for being able to change the functions inside the system and flexibility for growing and expanding. Because of this we wanted our design method to be based on modules, which we think is the best way to allow such function, i.e. flexibility. 
A modular system for the health center has many advantages [46]. First of all, it facilitates the design process and gives the project an interesting architectural quality, since the whole structure is going to be based on one single module changing functions as it is repeated, finally managing to create other structures that are designed not only for health purposes, but also public spaces with different community services such as education, market areas etc.

Our design for the modules is based on the use of a central plan. In three groups, we examined different ways to produce central plans, using basic elements such as sets to create different spaces. We avoided naming the spaces with various functions, to make the first health center module as flexible as possible.

We paid a lot of attention to both outdoor and indoor spaces, considering that the outdoors could be dedicated to common activities and could represent an attractive space for people. In order to make the health center even more inviting and suitable to the environment we are working on, we tried to use particular shapes and elements recalling the surroundings.

Our challenge was to create a prototype that could be used in the whole continent of Africa. This prototype, which was interpreted as a module, had to be easily adaptable in different countries, changing simple characteristic elements and materials based on the local construction methods.

\section{CONCLUSION}

The important role of PHC, and in particular the role of the Health Post in rural districts is essential and should be able to grow, thus generating settlement and integrating still weak peripheral segments into the health system.

This study aims to identify the course of action that can best ensure the constructive procedure of the Health Post, by inserting it in a program that includes:

- support to decentralization processes and promotion of these Health Posts within the integrated local development systems;

- support to local institutions (rather than replacement) in the management of resources, ensuring efficiency, effectiveness and transparency;

- the involvement of civil society in the identification of priorities, resource planning and evaluation of results;

- the pertinence and cultural sustainability, social, environmental and economic of the intervention;

- the appropriate use of different financial instruments, and methods of implementation of cooperation activities in the field of social health.

Finally, thanks to these studies we learned how to create architecture in different circumstances and the importance of being able to give an architectural interpretation to one of the biggest problems in the world. This research tries to demonstrate that the influence of architecture is strongly positive and contributes to improving life quality in every scale and context. 


\section{REFERENCES}

[1] Van Damme, W., Van Lerberghe, W. \& Boelaert, M. (2002) "Primary health care vs. emergency medical assistance: a conceptual framework", Health Policy and Planning, 17, No.1, pp 49-60.

[2] Falasca, C.C. (2000) Architetture ad assetto variabile: modelli evolutivi per l'habitat provvisorio, Florence: Alinea.

[3] Zhang, G., Setunge, S. \& van Elmpt S. (2014) "Using shipping containers to provide temporary housing in post-disaster recovery: Social case studies", Procedia Economics and Finance, 18, pp 618-625.

[4] Economist Intelligence Unit (2011) The future of Healthcare in Europe. See also "The role of research for universal health coverage" (2013) in The World Health Report 2013, Geneva: WHO Press, pp 5-30.

[5] "How research contributes to universal health coverage" (2013) in The World Health Report 2013, Geneva: WHO Press, pp 57-94.

[6] ONU Déclaration universelle des droits de l'homme (1948) Adopted and proclaimed by the General Assembly of United Nations in its Resolution 217A (III), art. 25.1.

[7] The International Conference on Primary Health Care (PHC) in Alma-Ata, Kazakhstan, in 1978, brought together 134 countries and 67 international organizations. The conference defined and granted international recognition to the concept of Primary Health Care as a strategy to reach the goal of Health for All in 2000.

[8] Between the 3rd and the 7th of August 1987, the WHO organized an interregional meeting in Harare. The meeting, which was about the implementation of primary health care (following up of the Alma Ata conference in 1978), ended with a statement that is known (or forgotten!) today as the Harare Declaration. By establishing the health district model as a reference strategy to organize and develop health services, this event shaped health systems in many poor countries. This strategy particularly shaped health service provision in rural Africa.

[9] Van Damme, Van Lerberghe \& Boelaert, "Primary health care vs. emergency medical assistance: a conceptual framework", pp 49-60.

[10] Kleczkowski, B.M. \& Pibouleau, R., (1983) "Approaches to planning and design of Health Care Facilities in Developing Areas in Division of Strengthening of Health Services", World Health Organization, Geneva, 4, No.72.

[11] AFRO Library Cataloguing-in-Publication Data, Atlas of Health Statistics of the African Region 2011, Brazzaville, Republic of Congo: World Health Organization. Regional Office for Africa, 2011.

[12] Purves, G. (2002) Healthy living centres: a guide to primary health care design, Oxford: Architectural press.

[13] Mac Lamprecht, B. (2000) Richard Neutra: complete works, Koln: Taschen, pp 28-29, 72, 84$86,160,176-178,242-243$.

[14] Hines, T. S. (2005) Richard Neutra and the search for modern architecture, New York: Rizzoli, pp 193-197.

[15] Centre pour le Bien-être des Femmes in Ouagadougou, BurkinaFaso (2005-2008) http://www.farestudio.it/cbf/

[16] Surgical Clinic and Health Centre in Lèo, Burkina Faso (2014) http://www.kerearchitecture.com/projects/clinic-leo/

[17] Pediatric Health Clinic in East Africa (2009) http://www.farestudio.it/pediatric-health-clinic/

[18] Cammock, R. M. (1981) Primary health care buildings: briefing and design guide for architects and their clients, London: Architectural press.

[19] Chizzoniti, D., Beggiora, K., Cattani, L. \& Moscatelli, M. (2014) "Health Post: A Sustainable Prototype for the Third World", World Academy of Science, Engineering and Technology International Journal of Civil, Architectural Science and Engineering, 8, No.4, pp 56-61.

[20] Stone, P. (1980) British Hospital and Health-Care Buildings, Design and Appraisals, London: Architectural Press.

[21] Purves, Healthy living centres: a guide to primary health care design.

[22] Akande, T.M. (2004) "Referral system in Nigeria: study of a tertiary health facility", Annals of African Medicine, 3, No.3, pp130-133.

[23] Dye, C., Boerma, T., Evans, D., Harries, A., Lienhardt, C., McManus, J., Pang, T., Terry, R. \& Zachariah, R. (2013) "Building research systems for universal health coverage", in The World Health Report 2013, pp 95-128. 
[24] Van Lerberghe W. \& Lafort, Y. "The Role of the Hospital in the District, Delivering or supporting primary care?", Current Concerns, 2, World Health Organization, 1990.

[25] Economist Intelligence Unit (2011) The future of Healthcare in Europe.

[26] Darkoh, E. (2003) The Masa Antiretroviral Therapy Program in Botswana, Presentation to the Bill and Melinda Gates Foundation.

[27] Darkoh, The Masa Antiretroviral Therapy Program in Botswana, Presentation to the Bill and Melinda Gates Foundation.

[28] Kleczkowski \& Pibouleau, "Approaches to planning and design of Health Care Facilities in Developing Areas in Division of Strengthening of Health Services".

[29] Kleczkowski, B. M. \& Nilsson, N.O. (1984) "Health care facility projects in developing areas: Planning, implementation, and operation", World Health Organization, Geneva.

[30] Feikin, D.R., Nguyen, L.M., Adazu, K., Ombok, M., Audi, A., Slutsker, L. \& Lindblade, K.A. (2009) "The impact of distance of residence from a peripheral health facility on pediatric health utilization in: rural western Kenya", Tropical Medicine and International Health, 14, No.1, pp 54-61.

[31] Doherty, J., Rispel, L. \& Webb, N. (1996) "Developing a plan for primary health care facilities in Soweto, South Africa, Part II: Applying locational criteria", Health Policy and Planning, 11, No.4, pp 394-405.

[32] Biolcati Rinaldi, M., Venturi, L. (2011) Architettura Sanitaria di Emergenza, Strutture Permanenti Realizzate con Tecnologie Appropriate, Bologna: CLUEB.

[33] VV.AA, (2006) Voci di tecnologia dell'architettura, Cavriana: Tecnologos.

[34] Staib, G., Dörrhöfer, A. \& Rosenthal, M. (2010) Atlante della progettazione modulare: elementi, sistemi, nuove tecnologie, Torino: UTET scienze tecniche.

[35] Kleczkowski \& Nilsson, "Health care facility projects in developing areas: Planning, implementation, and operation".

[36] Falasca, Architetture ad assetto variabile: modelli evolutivi per l'habitat provvisorio.

[37] Kleczkowski \& Pibouleau, "Approaches to planning and design of Health Care Facilities in Developing Areas in Division of Strengthening of Health Services".

[38] Kleczkowski \& Nilsson, "Health care facility projects in developing areas: Planning, implementation, and operation".

[39] Cammock, Primary health care buildings: briefing and design guide for architects and their clients.

[40] Orofino, E. (1983) Primary Health Care Centres Under Conditions of Limited Resources, A methodology for an integrated planning, Torino: C.L.U.T.

[41] Stone, British Hospital and Health-Care Buildings, Design and Appraisals. See also: Anthony Cox, Philip Groves, (1995) Ospedali e Strutture Sanitarie, Dario Flaccovio Editore, Palermo, pp 2-23, 34-38, 68-79.

[42] Valins, M. (1993) Primary health care centres: a review of current trends and the future demands for community-based health care facilities, Harlow: Longman. See also: Van Damme, Van Lerberghe, Boelaert, "Primary health care vs. emergency medical assistance: a conceptual framework", pp 49-60.

[43] Van Lerberghe \& Lafort, "The Role of the Hospital in the District, Delivering or supporting primary care?". See also: Wim Van Lerberghe, X. de Béthune, Vincent De Brouwere, (1997) "Hospitals in sub-Saharan Africa: why we need more of what does not work as it should", Tropical Medicine and International Health, 2, No.8, pp 799-808.

[44] Purves, Healthy living centres: a guide to primary health care design.

[45] Cindy-Lee Dennis, (2003) "Peer support within a health care context: a concept analysis", International Journal of Nursing Studies, 40, pp 321-332.

[46] Staib, Dörrhöfer \& Rosenthal, Atlante della progettazione modulare: elementi, sistemi, nuove tecnologie. 


\section{Authors}

1. Domenico Chizzoniti graduated in 1996 at Politecnico di Milano (100/100 with honour). He obtained a PhD degree in Architectural Composition in 2001 at IUAV of Venice. Assistant Professor at the Department of Architectural Design of the Politecnico di Milano since 1996. Between 2002 and 2005 he worked as a Lecturer at Faculty of Architecture of the Università degli Studi Parma and at the Faculty of Civil Architecture of the Politecnico di Milano. In 2008 he became an Assistant Professor in Architectural Composition at Politecnico di Milano, and in 2015 Associate Professor. He is a coordinator of the publications of TECA "Teorie della Composizione Architettonica". He has published more than 80 scientific papers in the field of Architectural Design.

2. Letizia Cattani is Lecturer and Research Assistant at the Politecnico di Milano. She obtained a PhD degree in Architectural Composition in 2010 at the Politecnico di Milano. She is the co-author of several papers about architectural design and the theory of composition in architecture. She is responsible of a Architectural Design Studio at Politecnico di Milano where she is focused on the topic of emergency structures in the Third World. At the moment she is working on a research about architectural design in developing countries and, in particular, she is interested on flexible and modular architectures used to realize typical aggregations that can be modified according to several users.

3. Monica Moscatelli graduated in Architecture in 2013 at the Politecnico di Milano (110/110 with honour). She is $\mathrm{PhD}$ Candidate at ABC Department (Architecture, Built environment and Construction engineering) of the Politecnico di Milano since 2014. Her main research topic is about Social and Health facilities for "Primary Health Care" in Developing Countries. From 2013 she is Tutor at Architectural Design Studio of the Politecnico di Milano. She attended during her Master degree in Architecture, the workshop "Ex area Falck" in close collaboration with Renzo Piano Building Workshop and Bizzi\&Partners. She published several scientific papers in the context of international conferences in the field of Architectural Design, Architecture and Social Development and Urban Planning.

4. Luca Preis is Lecturer and Research Assistant at the Politecnico di Milano, where he teaches Architectural Design. He is co-author of several papers about architectural design and redevelopment of the urban city centre; his articles have been published in journals of architecture and urban planning, and he has participated in international conferences on the theme of urban regeneration. In these last few years he is working to set up a research on a specific case study, represented by the city of Fidenza, included in the basin of the Po valley, along the Via Emilia, with the purpose of showing a critical approach, able to express the potential of the small central dismissed areas in the process of urban
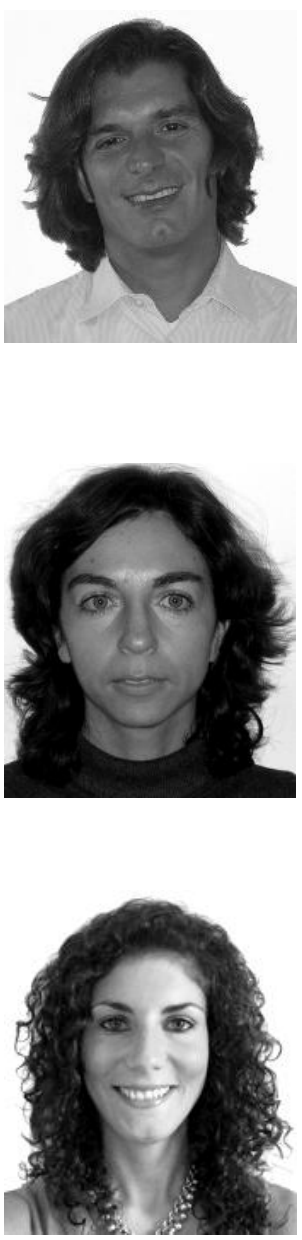
regeneration.

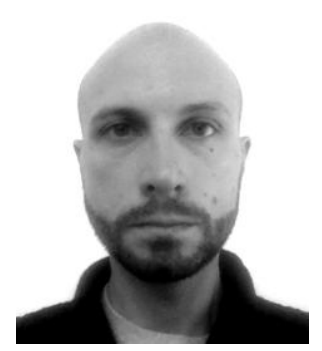

